\title{
Tacit knowledge management at universities in Kenya
}

Joan Wakasa Murumba, Kisii University and Karatina University, Kenya, jwakasa@karu.ac.ke

Tom Kwanya, The Technical University of Kenya, Kenya, tom.kwanya@gmail.com

Jane Cherono Maina, Kisii University, Kenya, janermaina@gmail.com

Aleso S. Wangamati, Kisii University, Kenya, dr.aleso@gmail.com

\begin{abstract}
Tacit Knowledge (TK) is a resource that is embodied within individuals in the form of experiences, ideas, beliefs, values, and norms. The specific objectives of this study were to examine TK assets at universities in Kenya and establish how TK is managed at universities in Kenya. Qualitative research approach was adopted and multiple case studies through purposive sampling to explore how universities in Kenya are managing their TK. Data was collected through interviews from 39 key informants from the four case study sites. Data was analysed using; conversation analysis, computer assisted qualitative data analysis, and chi-square tests. This study is important because TK is quite essential for institutional functioning and progress. This study identifies human, innovation, and relational capital as assets that have helped institutions to grow in terms of work processes, decision making and creation of new products and/or services. Institutions may need to develop TK assets as tools of their core development goals. The findings of this study can influence TK management policy formulation.
\end{abstract}

Keywords: Organizational Performance, Tacit Knowledge, Tacit Knowledge Assets, Tacit Knowledge Management, Universities in Kenya.

\section{Introduction}

Many countries in Africa have not been able to wholly implement Knowledge Management (KM) in their operations because knowledge has not been fully embedded despite the presence of Information and Communication Technology (ICT) policies (Ondari \& Minishi, 2007). According to the frameworks' parameters on education, innovation and ICT, Kenya scored $1.83 \%, 4.18 \%$, and $2.28 \%$ respectively (World Bank, 2012). Kenya is performing poorly especially in education, innovation and ICT by scoring below average in a scale of 1-10. Universities in Kenya were established in different years and were also awarded charters at different times. Kenya has 74 universities out of which; 31 public, six public constituent colleges, 18 private, five constituent colleges, all charted, while 14 others have letters of interim authority (CUE, 2017). These universities are geographically scattered in the country. This, therefore, is an indicator that their level of tacit KM is probably different and at different stages. Public universities depend on government funds to support their operations which is declining by the day. To remain competitive, these institutions need to engage in diversified commercial activities to substitute this 
funding in order for them to support development projects for expansion and growth; tacit KM is just one of the strategies universities can adopt to develop initiatives. Government funds are insufficient as evident with universities facing infrastructural challenges.

Tacit Knowledge Management (TKM) is a complex activity that requires a well-structured model to manage. Universities are knowledge centres. A knowledge centre is a structured unit established by an institution for handling knowledge assets. According to Skyrme (2001), "a typical knowledge centre will manage various knowledge resources - documents, databases, intranet content, expertise and directories" (p. 296).

Ministry of State for Planning, National Development and Vision 2030 (2012) recommend four elements that allow effective exploitation of knowledge: (a) an economic and institutional regime that provides incentives for the efficient use of the existing knowledge, the creation of new knowledge, and the flourishing of entrepreneurship; (b) an educated and skilled population that can create, share and use knowledge well; (c) a dynamic information and communication infrastructure that can facilitate processing, communication, dissemination; and finally (d) an effective innovation system (i.e. a network of research centres, universities, think tanks, private enterprises and community groups) that can tap into the growing stock of global knowledge, assimilate and adapt it to local needs, while creating new knowledge and technologies as appropriate. (p. 21)

Managing Tacit Knowledge (TK) assets through hiring and retaining academic and administrative staff who are gifted and experienced is a challenge in universities in Kenya today. Kipkebut (2010) observe that work related challenges "have led to the exodus of teaching staff to the private sector or abroad in search of better opportunities" (p. 9). This exodus poses greatest challenge to TK assets in the universities. If this is lost it means the organisation is bound to lose. The 2006 Public Universities Inspection Committees Report of the GoK indicates that staff who leave for further studies abroad do not return (Ng'ethe et al., 2012).

This paper is an exploratory study conducted to examine TK assets management at selected universities in Kenya. Theoretical issues discussed are TK assets; and TKM at universities in Kenya. Key KM processes of creation, storage, sharing and application and use were key elements that formed the research questions to help obtain data on how universities are managing their TK. Through the first objective on examining TK assets in universities in Kenya, valuable knowledge should be identified, and then represented as a map to show the connections between knowledge, people, and organisational units as well as to develop high-level classifications of the TK taxonomy. The knowledge map serves to identify not only who creates valuable knowledge, but who has, where it is and who else uses this knowledge. Universities, through knowledge audits can facilitate organisational growth by exploring TK (Chugh, 2019). This research is expected to persuade universities to put more emphasis on TKM and ways of harnessing TK within universities as well as other organisations altogether. "Organizations need a good capacity to retain, develop, organise, and utilise their employees' capabilities in order to remain at the forefront and have an edge over competitors" (Omotayo, 2015, p. 2). Most organizations have realized that, knowledge resources, are necessary for survival and sustainable development.

Universities in Kenya are struggling with achieving maximum organisational performance through TKM. Universities in Kenya are beleaguered with the growing customer knowledge needs, 
dynamism in technology, growth in student population while knowledge resources and financial to handle such pressure is minimal. Human efforts generate knowledge which can be developed through quality education, training, research, mentorship and creativity. The current study displays the value of human resources in TKM, which should be given great attention. Human resources are key drivers to TKM because they create, preserve, and transfer and share TK. Knowledge resides and originates from the human mind. Without the human resources no organisation would be refereeing to TK. This forms the primary basis of the paper. To support the discussion Boisot (1998)'s I-Space and Wenger (1998)'s communities of practices models were adopted. Gaps were identified from the empirical literature that formed the justification of the paper.

\section{Research Objectives}

This research's objectives were:

i) To examine $\mathrm{TK}$ assets in universities in Kenya

ii) To establish how TK is managed in universities in Kenya.

\section{Literature Review}

Universities are knowledge intensive organizations that promotes idea generation and sharing through there multifaceted systems that facilitates the process of knowledge processing (Martin \& Marion, 2005). In addition, the role of academic staff in universities is geared towards knowledge sharing and transfer which is a key facet of knowledge management (Rowley, 2000). Cheng et al (n.d.) noted that "it has always been a practice in almost all higher educational institutions to store all relevant documents contributed by in-house resources in the knowledge repository or the database" (p. 316). Most academic institutions have institutional repositories with scholarly publications developed by students and the members of staff as a sign of knowledge management. However, Keramati and Azadeh (2007) observed that the same "organizations face innumerable challenges in nurturing and managing knowledge" (p. 59). TK is not easy to handle. Keramati and Azadeh (2007) further noted that:

Knowledge activities are difficult to monitor and control, because only a part of knowledge is internalized by the organization, the other part is internalized by individual. This duality between individual knowledge and organizational knowledge demands different sets of management strategies in knowledge management's success for the organization. (p. 59)

This is one of the greatest obstacles that universities should focus on addressing.

\section{Tacit Knowledge}

Polanyi (1966) viewed TK as knowledge that is hard to express. Polanyi suggested that "we can know more than we can tell" (p. 4). It is not easy to formalise this kind of knowledge. There are several ways and requirements for sharing TK. This can be through observation, experience sharing, social interaction, informal relationship and networking, and when there is mutual trust (Panahi et al., 2012). TK is an important resource that consists of "embodied expertise - a deep understanding of complex, interdependent systems that enables dynamic responses to contextspecific problems" (Wenger et al., 2002, p. 9). "To manage intangible assets such as knowledge is perceived to be an important capability for competition" (Haldin-Herrgard, 2000, p. 357). Awad 
and Ghaziri (2007) explained that TK is "knowledge embedded in the human mind through experience and jobs" (p. 71). While Alwis et al. (2014) indicated that TK is difficult to communicate. Whyte and Classen (2012) argued that "tacit knowledge has a personal component which makes it difficult to formalise and communicate as it consists of technical expertise, often denoted as know-how; and cognitive dimension that includes schemes, ideas, mental models, beliefs and perspectives" (p. 951).

Lee and Nissen (2010) as well as Mungai (2014) indicated that although TK is valuable to organisations, it has been neglected and is not well understood especially by public organisations. For instance, "educational organisations are not yet able to embrace KM and are not yet conscious of the crucial importance of tacit knowledge" (Banacu et al., 2013, p. 491). Mungai (2014) noted that "institutions spend much more in managing explicit knowledge that is recognisable, and as such, they could potentially lose the competitive advantage for organisational development and growth over other institutions in performance and target delivery" (p. 4). TK is "embodied in the individual firm, rooted in practice and experience" (Zhao, 2013, p. 571).

Universities can take advantage of the TK resources in their possession. This enables such institutions to utilize the competences of such TK assets. Wang et al. (2015) noted that, for an academic institution to succeed, it must effectively manage its knowledge resources in order to improve in teaching and learning; staff retention; developing new programmes, products, and services; offering mentorship; improving cost efficiency; providing flexible learning platforms; and meeting of students' needs whenever required.

\section{Tacit Knowledge Management (TKM)}

Banacu et al. (2013) stated that TKM:

Entails both object-oriented thinking and process-oriented thinking. The object-oriented perspective implies a focus on data storage; tools, document sharing and transfer. Thus, treating TK as an object supposes investment in information technology, where information technology acts as a facilitator in TK capturing and sharing. (p. 498)

Technological components in the form of social media are seen to be facilitators of TK sharing as revealed by Khamali et al. (2018) study findings which discovered that "social media tools (Facebook, WhatsApp, Twitter, \& blogs) resulted in better communication, collaboration, interaction and knowledge sharing amongst the students in Kenyan universities, and hence generally improved knowledge sharing" (p. 1817). Banacu et al. (2013) further explained that "the process-oriented perspective on the other hand implies a focus on collaborative processes and learning dynamics, and therefore involves investment in people" (p. 498).

TKM in universities intends to extract value from identified TK resources which could improve performance. Universities have displayed certain efforts in their contest to manage TK. For example, outlined activities and practices like, mentorship, career fairs and innovation weeks, workshops and conferences among others. TK can be managed through, TK creation/capturing, storage/retrieval, sharing/transfer and application strategies. Kidwell et al. (2000) indicated that "capturing the tacit knowledge of the individuals and making it widely and easily available to the faculty members and other constituents bears great importance. The ability to manage tacit knowledge promises to deliver huge returns for organizations" (p. 31). Such knowledge allows 
individuals to work on their own without consulting, they are able to run organisational operation, thus saving turnaround time.

TK sharing is additionally another important management mechanism. Sharing TK can be through available connections. Individual's ability or an organisation to expand their knowledge base lies in connections. Such networks and contacts created help one to; seek out new and diverse experiences, question the status quo, try out the new surroundings from a variety of fields, and observe new contexts (Gallo, 2010). This in itself provides a solid platform for TKM in universities. Successful knowledge-creating companies encourage their workers to develop these attitudes and skills; they want them to take risks, to talk to and observe one another, to keep an attitude of curiosity, wonder, amazement (Palmer et al., 2010), and they give employees the opportunity to make mistakes. "Colleges and universities exist to create and share knowledge" (Serban \& Luan, 2002, p. 1).

Currently, the world has transformed with organizations becoming more service and innovation oriented. This makes TK a significant asset to address the dynamism in the society. Global Sustainable Development Goal number nine on industry, innovation and infrastructure cannot be overemphasized (UNDP, 2015). TK sharing among employees is critical and it gets lost especially with job hopping and high turnover rates (Mayfield, 2010). Sharing such valuable knowledge should be done before it disappears from the organisations. TKM can also:

Transform organisational new levels of effectiveness, efficiency, and scope of operation, using advanced technology, data and information made available to users for effective productivity). Knowledge Management processes provides procedures for capturing tacit knowledge hidden in experts' individual mind and practices and preserves it for future use. $\mathrm{KM}$ is continually discovering organisational tacit knowledge. It is also useful for building tacit knowledge, for problem solving and decision-making purpose. Quality and service improvement in universities can also achieved through TKM. (Dhamdhere, 2015, p. 168)

There are a number of challenges faced by universities during the process of managing TK. Firstly, is the challenge to capture TK. Gill (2009) studied KM initiatives at a small university where capturing knowledge of senior staff was identified a problem. Dhamdhere (2015) observed that "generated knowledge in the universities is not captured properly and many times it is also not known to any one and remains as grey literature, which might be useful if proper recording is maintained in the organisation" (p. 1). The process of capturing TK is complicated and involves time management, commitment, tools and technologies, methods, and procedure (Awad \& Ghaziri, 2007). TK cannot be captured by ICT systems because of its intangible nature (Bhardwaj \& Monin, 2006). "Tacit knowledge embodied in humans, require technologies which can support, capture and enhance activities such as group work, guided experiments, simulations, meetings, mentoring, apprenticeship and online and offline socialisation" (Kabir, 2013, p. 241). Technology is only an enabler to the TK creation process. Kabir (2013) added that "importance should be given not just to have these activities captured in multimedia and other repositories but the KM framework must also facilitate integration and access to all information upon request in a simple user-friendly manner" (p. 241). Secondly, "tacit knowledge is practical knowledge, that is, the key to getting things done, but it has been neglected in the past" (Vahedi \& Irani, 2010, p. 445). TK that is significant is not easy to flow in the organisation due to its stickiness (Mungai, 2014). 
Reportedly, more than $80 \%$ of the knowledge in any organisation is embedded and synthesised in peoples' heads (Bonner, 2000a, 2000b; Lee, 2000; Wah, 1999a, 1999b). If the personnel get lazy, inactive, and sluggish in their work then they pose a challenge to TK creation. Human beings are in themselves the greatest obstacles to TKM (Wah, 1999a, 1999b). Individuals are affected by internal and external factors in their pursuit to TK creation. When TK of staff cannot be captured and shared easily it becomes a major challenge to its management. A poor culture of TK sharing can affect other university initiatives like coaching and mentorship.

Thirdly, TK loss poses a major challenge to TKM in universities. Lahaie (2005) observed that:

Regardless of how well senior management is able to manage knowledge within the organization and regardless of what processes are in place to transfer knowledge to the employees either within or to those entering the organization, there will always be some degree of corporate memory loss when a long-term employee leaves. (p. 40)

When employees are not well taken care of, they become less concerned and less productive. They feel devalued and the result is demotivation, unproductive and lack creativity. Taking advantage of employees as TK resource means that the universities take cognizant of them, this in turn makes them feel valued which triggers employees support in terms of productivity, efficiency and effectiveness. Lahaie (2005) found out that:

$42 \%$ [sic.] of corporate knowledge resides in the brains of the people who work in the facility. The memory that accompanies the person out the door is both explicit and tacit, based on information that was gained through the experience of having been in the institution. (p. 40)

To overcome some of the TKM challenges, institutions are trying to put in place mechanisms to support management of these important resources. This includes TK preservation, succession planning and transformational leadership.

\section{Theoretical Frameworks}

Boisot (1998)'s I-Space and Wenger (1998)'s Communities of Practice (CoP) models were adopted since they provide significant components that supports TKM.

\section{Wengers' Communities of Practice (CoP) Model}

Wenger et al. (2002) defined CoP "as groups of people who share a concern, a set of problems, or a passion about a topic, and who deepen their knowledge and expertise in this area by interacting on an ongoing basis" (p. 4). The model has three main elements: domain, community, and practice (Wenger et al., 2002). Domain is a body of knowledge on which the community is interested. Membership therefore implies a commitment to the domain, hence a shared competence that distinguishes members from other people (Wenger, 2010). In the university setting, members of staff (both teaching and non-teaching), students and the external community can form part of the domain according to their areas of competence. Community allows members of a domain to engage in joint activities and discussions, help each other, and share and exchange knowledge. They build relationships that enable them to learn from each other (Wenger, 2010). Universities have sections from which members can form groups according to their areas of specializations and 
interests. CoP allows members of the community to share knowledge resources through experiences, stories, tools, best practices, and ways of addressing recurring problems. Practice in CoPs takes time and continuous interaction (Wenger, 2010). CoPs have both formal and informal activities which provide a platform for learning. The research objective of this study is to establish how TK is managed in universities in Kenya. A number of elements have to be set up for TK to be managed. TK creation and sharing are examples of such elements. Formal learning processes like coaching and mentorship are inherent practices of a $\mathrm{CoP}$ which provides learners with a chance to learn from the experienced staff in the universities. The informal nature of the CoP allows university activities to be incorporated in the CoP. Mungai (2014) stated that:

Practitioners who are part of work groups, business processes or teams are also part of CoPs in the organisation. Mungai further noted that CoPs leverage the authority of managers and employees to be free to air their opinions on their expertise without fear, reprimand or intimidation as would be the case in an office hierarchy structure. This enables them to guarantee quality of output as opinions are shared and debated upon and later, the best option is used to solve challenges that had been presented at the work groups (knowledge capital applied). To this extent, TK shared is captured, validated and codified using enablers such as technology for future reference. (pp. 29-30)

Jakovljevic et al. (2013) classified "different areas of learner knowledge as TK, school knowledge, and innovative construct knowledge" (p. 1110). On the other hand, Evans (2003) classified knowledge as "explicit (that exits typically in documents, databases and as part of processes) and tacit (embedded in people and their experiences)" (p. 17). Jakovljevic (2013) further contended that:

Over time successful CoP activities can influence learners' personal innovation construct. Knowledge creation is a process of communication between explicit and TK. The strength of learners' knowledge activities lies in the transfer and integration of TK through activities within CoPs. TK can be shared and integrated through a network of social interactions of which the CoP is one such social interaction platform. Social networks within CoPs allow individuals to receive, evaluate, reflect, and return knowledge. (p. 1110)

Furthermore, Jakovljevic (2013) agreed with Allam (2008) and McGuinness (2011) by noting that "it is necessary to pay attention to key elements to unlock creative inspiration, such as discipline, routine for creative work, one's own efficiency/construction system, and spontaneity" (p. 1111). Mentors, experts who are lecturers should take this upon them to provide leadership to their students and staff. The formation of incubation hubs/centres, innovation hubs and associations in universities shall support this important TK strategy. Such centres facilitate nurturing talents which triggers and fosters creativity that leads to TK creation. This, therefore, calls for management support, where the top management of universities should oversee the operations of such groups in the universities. Without management support and approval, it is difficult to realize such output.

\section{Boisot I-Space Model}

In 1998, Boisot proposed an I-Space model that depicts six main stages of transformation in three dimensions of information; codification, diffusion and abstraction, with an associated scale 
that ranges from codified to uncodified, from diffused to undiffused and from abstract to concrete as illustrated in table 1. According to Boisot (1998):

The term codified refers to knowledge that can be readily prepared for transmission purposes. Codified undiffused knowledge is referred to as proprietary knowledge and is deliberately transmitted to a small group of people, on a "need to know" basis. Secondly, uncodified refers to knowledge that cannot be easily prepared for transmission purposes such as know-hows. The model suggests that uncodified and undiffused knowledge is referred to as personal knowledge, for example, experiences, perceptions, views, ideas. This model suggests that there is diffusion of knowledge across organizations as reflected in the horizontal dimension of the model. The codified and uncodified categories in the model are discrete categories of knowledge (Haslinda \& Sarinah, 2009). Third, the left quadrant covers public knowledge and common sense knowledge. Public knowledge is codified and diffused, for example, library, journals, books, and newspapers. Finally, common sense is knowledge which is relatively diffused and uncodified and can gradually develop through the process of socialization and externalization. (p. 59)

Table 1. Boisot I-Space Model (Adapted from Boisot, 1998, p. 3)

\begin{tabular}{|c|l|l|}
\hline \multicolumn{2}{|l|}{ Three Dimensions of Boisot's I-Space Model } & SLC Phases \\
\hline 1 & Uncodified to Codified & $\begin{array}{l}\text { 1. Scanning } \\
\text { 2. Problem Solving } \\
\end{array}$ \\
\hline 2 & Concrete to Abstract & $\begin{array}{l}\text { 3. Abstraction } \\
\text { 4. Diffusion }\end{array}$ \\
& & $\begin{array}{l}\text { 5. Absorption } \\
\text { 6. Impacting }\end{array}$ \\
\hline 3 & Undiffused to Diffused & \\
\hline
\end{tabular}

Boisot (1998) proposed a Social Learning Cycle (SLC) that uses the I-Space to model the dynamic flow of knowledge through a series of six phases:

Scanning:

Identifying threats and opportunities in generally available but often fuzzy data weak signals. Scanning patterns such data unique or idiosyncratic insights that then become the possession of individuals or small groups. Scanning may be very rapid when the data is well codified and abstract, and very slow and random when the data is uncodified and context-specific; (p. 59)

Problem solving:

Is the process of giving structure and coherence to such insights - codifying them. In this phase they are given a definite shape and much of the uncertainty initially 
associated with them is eliminated. Problem-solving initiated in the uncodified region of the I-Space is often both risky and conflict-laden; (p. 59)

Abstraction:

"Generalizing the application of newly codified insights to a wider range of situations. This involves reducing them to their most essential features conceptualizing them. Problem-solving and abstraction often work in tandem" (p. 59);

Diffusion:

Sharing the newly created insights with a target population. The diffusion of wellcodified and abstract data to a large population will be technically less problematic than that of data which is uncodified and context-specific. Only a prior sharing of context by sender and receiver can speed up the diffusion of uncodified and concrete data. The probability of achieving a shared context is inversely proportional to the size of the target population; (p. 59)

Absorption:

Applying the newly codified insights into different situations in a 'learning-bydoing' or a 'learning by using' fashion. Over time, such codified insights come to acquire some context, that is, a penumbra of uncodified experience, which helps guide their application in particular circumstances; (p. 59)

Impacting:

"The embedding of abstract knowledge in concrete practices. Such embedding can take place in artifacts, technical or organizational rules, or in behavioral patterns. Absorption and impacting often work in tandem" (p. 59).

Boisot (1998)'s model is an important model for this paper because the model promotes TK, creation, sharing, and application as the key TKM processes to be implemented in universities. TK that is undiffused is highly tacit in nature and once it is codified it can be transferred to very few individuals and on very strict terms in a department or a school. Once an individual with such TK is identified they can be inspired and allowed to share the same with their colleagues in the universities. Providing and making available TK sharing platforms and structures in the universities will definitely facilitate creation and sharing of TK. Through this sharing university employees will obtain new ideas and skills which will improve on their areas of weaknesses and hence improved performance (Boisot, 1998). According to the fourth phase of the SLC, "diffusion, the new insights are shared with a target population in a codified and abstract form" (Boisot, 1998, p. 42). Once TK is diffused and engrained in the university system it would lead to growth and competitiveness. The more TK is shared, the more valuable it becomes. At the same time the undiffused TK assets in form of experience is equally very critical to an institution. Universities should take care of their experienced employees. These are TK wealthy individuals who can make or break an institution. Incentivizing and providing a conducive working environment to such staff is a worthy TKM investment. Having expert knowledge is an asset which makes an institution competitive, loosing such an individual would be a great loss. 
This is supported by Housel and Bell (2001 as cited in Mohajan, 2016, p. 14) who indicated that "valuable tacit knowledge is lost when skill and expert members exit the organization without having their knowledge documented". This element addresses the papers' objective on establishing how TK is managed in universities in Kenya. Kreiner (2002) noted that TK that is highly classified and abstract can be diffused to a large group of people. This is because codification is facilitated by categorization and grouping of related issues together. TK can be used for problem solving in the universities. Once employees have this kind of knowledge, they will be able to handle different situations and operations. Absorption phase of the SLC means that TK has been acquired through individual learning, this again is uncodified (Boisot, 1998) and will help individuals to apply such knowledge and skills in different working environments and contexts. This helps in performing routine work and employees would handle any case without having to waste time to consult and refer. By doing this, more tasks will be done and handled hence effective service delivery shall be realized. Impacting can be realized when the absorbed TK is incorporated into the organisational practices as rules, policies and procedures (Boisot, 1998). This integration supports knowledge application, which in an element of TKM. In addition, Mahroeian and Ferozia (2012, p. 306) indicated that "tacit knowledge can be found in routines, organizational culture and cognitive schemes". This can be evident by a TK sharing culture, where individuals start sharing knowledge willingly. Employees become critical and creative thinkers and hence innovators. New products and services will be developed with ease. This will make universities to be highly competitive. The issue of half-baked graduates, half-baked lecturers will become a thing of the past. At this stage commercialized products from students and staff shall be developed, which additionally addresses the implementation of the objective on TKM.

Mohajan (2017) agreed with Boisot and Canal (2004) who claimed that "the SLC provides a strong back up by linking content, information and KM. The codification dimension is linked to categorisation and classification, the abstraction dimension is linked to knowledge creation through analysis and understanding, and the diffusion dimension is linked to information access and transfer" (p. 21). Once the model is adopted, it will support universities in achieving greater improved growth and performance. Being in a dynamic knowledge society, Boisot (1998)'s ISpace model is relevant because of the phases of the SLC, which provides for dynamism and maturity at each phase (Boisot et al., 2003). As a TKM strategy, universities can adopt such a model to instill a culture of creating and sharing TK which would provide the basis for improved performance. Universities are knowledge organisations with TK embedded in people and processes (Nonaka \& Takeuchi, 1995). TK is a valuable resource for continuous improvement and for responding to the dynamic knowledge needs of the society.

\section{Methodology}

Given that this study is qualitative in nature, the key informants were purposively chosen. These are individuals with critical information to enrich this study. These key individuals are busy employees who attend regular university management meetings and therefore prompted the researcher to seek prior and regular reminders for appointments for interviews. The choice of the respondents was due to the nature, core mandate of the organisations and the day to day engagements of the personnel in the identified schools, departments, directorates and sections. 
This study was restricted to qualitative data collection tools which require enough and wellplanned time for data collection. We were able to plan their time together with the interviewees to avoid inconveniences. In some cases, we had a flexible interviewing schedule in case the respondent got held up with institutional emergencies. This study employed guided semistructured in-depth interviews. In addition, documentary analysis of secondary data complemented data gathered during the interview sessions.

The current study targeted both academic and administrative university staff in four out of seventyone universities in Kenya (CUE, 2017). These are: University of Nairobi (UoN), Kibabii University (KIBU), University of Eastern and Central Africa, Baraton (UEAB), and KCA University (KCAU). The four universities were identified on the basis of the length of time that they have been in existence. The year of establishment provided a chance to select two oldest and two young universities in Kenya. This study population were purposively identified as core study subjects because of their information and knowledge richness hence primary sources of data for the current study. The selection of the said institutions was done on the basis of the volume of TK which was determined by the year of establishment of the universities. Qualitative research approach was adopted to provide an in-depth description of the specific research problem which is TKM. Exploratory multi-case study design was adopted in order for the researchers to gain a detailed understanding of how universities are managing their TK. Purposive non-probability sampling was employed in selecting information-rich units in four case study sites in order to achieve the desired results. Additionally, this research obtained information about TKM from a total of (45) key resource persons in the selected institutions through face-to-face semi-structured interviews. These were (25) deans, (4) heads of planning and administration (PA), (4) heads of research, (4) heads of innovation divisions, (4) head librarians, and (4) ICT directors. Out of the 45 target informants, 39 were available for the interviews. Being the key informants, they provided adequate information because they interact with $\mathrm{KM}$ activities in their course of duty. The nature of the data collection allowed more information to be obtained. In addition, the researcher probed respondents for clarity. Besides, the researchers reviewed published reports, websites and policy documents obtained from the four universities, with the aim of providing evidence of TKM and organisational performance in these universities.

\section{Data Collection Tools and Procedure}

Data collection tools used by this study included interviews and document analysis. We conducted interviews with deans, heads of ICT, head librarians, heads of research and/or innovation, and head of planning and administration sections in the universities. Data was collected through in depth semi structured interview schedules - which is a schematic presentation of questions or topics and need to be explored by the interviewer, for each category of respondents (Corbin \& Strauss, 2008). Interviews help in probing the interviewees for in depth information that cannot be obtained by administering questionnaires. Before proceeding to the field, appointments were booked and confirmation calls made. The interviewees provided their most appropriate time for days the interviews were scheduled. Each participant was interviewed for at least 40 minutes guided by the interview schedules. A dedicated notebook was used to record further responses that emerged during the process. The guided semi-structured questions allowed maximum concentration without digressing. Three weeks were spent at each study case with daily visits. 
Besides interviews, document analysis was used in collecting secondary data. While visiting the institutions to interview the key informants, permission to access specific documents that could augment the information collected during the interviews was sought. The documents were read and the content analysed to find further evidence of TKM in those institutions. This was done especially during the hours when the participants were engaged in other university activities. In addition, during the daily visits, two hours were dedicated to examine the documents during the research period at the institution. Such documents included: performance contracts, mentorship policies, staff appraisal forms, policies (ICT, library) research, and innovation policies.

\section{Data Analysis}

Taylor-Powell and Renner (2003) indicated that "qualitative data for the most part consists of words and observations, and like all other data requires analysis and interpretation to bring order and understanding" (p. 1). "Qualitative analysis transforms data into findings which involves; reducing the volume of raw information, sifting significance from trivia, identifying significant patterns and constructing a framework for communicating the essence of what the data reveal" (Patton, 2002, p. 432). Best and Khan (2006) further detailed steps for qualitative data analysis. First, is organizing the data, and second is describing the various pertinent aspect of the study. Patton (2002) described the third step as "interpretation which involves an explanation of the findings which aims at answering why questions, attaching significance to particular results, and putting patterns into an analytic framework" (p. 434). Questions for collecting qualitative data were aligned to this study's objectives as follows: what are the TK assets in universities in Kenya? and how is TK managed in universities in Kenya? The researcher applied a combination of data analysis techniques to accommodate all types of data collected during this study. Hoey and Kendrick (2017) defined "Conversation Analysis (CA) as an inductive, micro-analytic, and predominantly qualitative method for studying human social interactions" (p. 2). Its "purpose is to characterize and explain the ways in which those engaged in conversation maintain an interactional social order by examining the technology of conversation" (Sacks, 1992, p. 339). Emerging themes were coded, categorized (thematic, analytical and natural categories) and then presented and discussed case by case. Kripperndorff (2004) defined content analysis as "a systematic reading of a body of texts, images, and symbolic matter not necessarily from an author's or user's perspective" (p. 3). Using this technique, the researcher was able to analyse primary documents in relation to TKM and performance in universities in Kenya. The documents included policies (HR, ICT, Library, research, \& innovation), newsletters, appraisal forms and brochures. These provided insights on how universities are taking care of TK in terms of motivation, rewards, appraisal, promotions, recognition, and general management.

Computer Assisted Qualitative Data Analysis Software (CAQDAS) (Estrada, 2017) was used to analyse qualitative data. This data was then coded and run using $\mathrm{R}$ software package to generate themes and categories. NVIVO was used to classify, sort, manipulate and store qualitative data. Data was then examined and related data linked, organised by themes, and presented. Onchiri (2013) stated that "one of the most common statistical tests for qualitative data is Chi-square $\left(\chi^{2}\right)$ tests" (p. 1233). Additionally, "Chi-square statistic is commonly used for testing relationships between categorical variables" (Patil, 2018, p. 1).

Kothari (2007) stated that: 
Chi-square has the goodness of fit test and test of independence. A test of goodness-of-fit establishes whether or not an observed frequency distribution differs from a theoretical distribution, and a test of independence assesses whether paired observations on two variables, expressed in a contingency table, are independent of each other. The Chi-Square test of independence determines whether there is an association between categorical variables (i.e., whether the variables are independent or related). It is a nonparametric test. The Chi-Square test of independence can only compare categorical variables. It cannot make comparisons between continuous variables or between categorical and continuous variables. Additionally, the Chi-Square test of independence only assesses associations between categorical variables, and cannot provide any inferences about causation. (pp. 3942)

It is important for this study to show the association between the categorical variables that emanated from the research to show how they affect the performance in universities in Kenya. The chi-square test specifically was used for the second study objective on how TKM (creation, storage, sharing, \& use) affects performance at universities in Kenya.

\section{Findings and Discussions}

The current research targeted 45 key respondents out of which, 39 key informants were interviewed. This is $86.67 \%$ response rate. This section presents findings on TK assets and management of the same. The section highlights what exists in the universities and how they are ranked in order of importance.

\section{Tacit Knowledge Assets}

A chi square test was performed to examine whether there is an association between $\mathrm{TK}$ assets and TKM. Table 2 represents the contingency table and the chi square test results for the relationship between the two variables.

Table 2. Chi-Square Test for Independence between TKA and TKM

\begin{tabular}{|c|c|c|c|c|c|}
\hline \multirow{2}{*}{ TKM } & \multicolumn{5}{|c|}{ TKM Process } \\
\hline & Creation & Sharing & Storage & Use & Row Total \\
\hline Human Capital & 11 & 8 & 0 & 5 & 24 \\
\hline Relational Capital & 3 & 2 & 0 & 3 & 8 \\
\hline Innovation Capital & 3 & 0 & 4 & 0 & 7 \\
\hline Column Total & 17 & 10 & 4 & 8 & 39 \\
\hline $\begin{array}{l}\text { Statistics for All Ta } \\
\text { Pearson’s Chi-squa } \\
\mathrm{Chi}^{\wedge} 2=23.29485\end{array}$ & & d.f. $=6$ & $\mathrm{p}=0.0007 \mathrm{C}$ & Statistics for All Table Factors & \\
\hline
\end{tabular}

Out of the three identified intellectual property assets, human capital was ranked the most important at $61.54 \%$. Out of 39 respondents, 24 acknowledged the key role played by human capital in TKM. Relational capital came second at eight $20.51 \%$, while innovation capital was ranked third at seven (17.95\%). In addition, three respondents noted that the three types of TK assets are equally important despite their ranking in order of priority (see results in Table 1 above). 
Human capital was found to be a key asset in TKM. This is because in all the four universities the respondents appreciated the role played by TK in improving performance. Even though this was noted, universities had problems of explicitly categorising this kind of knowledge asset. This therefore means, taking care of such resources was a problem. Lack of structures in place demonstrated the inability of TK asset management. According to Sharkie (2005), "tacit knowledge is the most important strategic resource that enables organizations to exploit and develop resources that enhances their fundamental ability to compete, meet the challenge of change and allows them to develop sustainable competitive advantage" (p. 37). Employees who are equipped with knowledge can guide an organisation to achieve its goals. Lack of TK results in stagnation in the growth of an organisation. TK is considered the most important asset in universities in Kenya. This is backed up by Hau et al. (2013) who asserted that explicit knowledge sharing requires less effort to share than tacit knowledge from employees. There was a significant association between TK assets and TKM since the p-value for the chi-square test was less than 0.001. Further, from the mosaic or association plot below it is clear that TK creation, sharing and use is heavily done by human capital and relational capital. TK storage is a problem and is heavily facilitated by innovation capital. There are no structures to support TK application and use. This leaves universities with no choice other than embracing TKM. This view simply emphasises the uniqueness of human skills and abilities in creating knowledge. Level of education, skills and qualifications, creativity, work experience and abilities of the employees add economic value to universities and the economy as a whole. Skills and qualification without social and communication skills is problematic. It means knowledge cannot to be shared due to poor communication skills. "Social interactions between and among people may be the route through which we acquire tacit knowledge, in that new knowledge is thought to be created through iterative social interaction (Nonaka \& Tackeuchi, 1995), but not as first advocated, by making tacit knowledge explicit" (Ryan \& Lero, 2012, p. 2). Polanyi (1966) established that TK transfer can only take place through close interaction. Employees with bad habits and poor personality negative energy, poor team players, poor time managers are unproductive hence pool down the performance scale. The best employees are brands - iconic figures who are productive hence generate income to the institutions. Such individuals should be well taken care of because of the expert knowledge.

\section{Tacit Knowledge Management (TKM) Processes}

The paper identified TKM processes as; TK creation and capture, TK storage and retrieval, TK sharing, and TK application and use.

\section{Knowledge creation and capture}

This research wanted to establish how TK is created and captured at universities in Kenya. From Table two below, it can be seen that respondents identified TK creation platforms as: research and innovation teams (25.9\%), documentation (22.4\%), learning processes (13.8\%), mentorship programmes $(10.3 \%)$, and capturing as done by research and innovation teams $(20.5 \%)$. Others identified documentation (17.9\%), learning processes $(15.4 \%)$, ICT and social media platforms $(10.3 \%)$, mentorship programmes $(10.3 \%)$, workshops and conferences, social media platforms and technology all at (5.2\%). 
Table 3. Creation and Capture of TK

\begin{tabular}{|l|c|c|}
\hline Creation platforms & Frequency & Percent (\%) \\
\hline Capturing is tricky, supported by technology & 3 & 5.2 \\
\hline Learning Processes & 8 & 13.8 \\
\hline Documentation & 13 & 22.4 \\
\hline ICT/ Social media platforms & 3 & 5.2 \\
\hline Mentorship Programmes & 6 & 10.3 \\
\hline No Mechanism & 7 & 12.0 \\
\hline Research and Innovations teams & 15 & 25.9 \\
\hline Workshops and Conferences & 3 & 5.2 \\
\hline
\end{tabular}

Just like any other company or organisation, universities employ staff who are either fresh from college or from the industry and lack experience in the higher education setting. The staff are employed on different terms; contract, temporary, casual or permanent and pensionable. After they are recruited, the staff are placed and/or deployed to different organisational departments or sections. Regardless of the terms of service or section deployed, training of such staff is important. This is so, because such groups of individuals need induction and exposure to the new environment. It emerged during the interviews that TK creation/capture is a difficult process. Respondents indicated that capturing this type of knowledge was tricky. They identified important ICT tools like, recorders, video tapes and cameras that can be used to capture TK. In the current knowledge economy, universities must manage TK. It was noted that in the universities under study, there were no complex ICT infrastructure apart from the ordinary ICT facilities. Respondents agreed that they use electronic media to capture TK. Social media was found to be a facilitator in knowledge creation and capture. The libraries in the case study sites use social media to collect information. Furthermore, knowledge was captured by employees through video recordings of meetings, as well as organisational documents, like the minutes of meetings and documentaries. In addition, this study finding revealed that universities create TK through experience of the human resource as supported by the mentorship programmes, and the learning processes. Ways to teach both TK and formal academic knowledge or job skills are similar. Universities indicated that they practice mentorship though it was informally done. Mentorship provides one of the key platforms of knowledge creation and capture. Workshops and conferences are also used as ways of creating TK. Such platforms are common in the education sector. Universities place call for papers, where individuals identify themselves with the proposed themes for writing papers for research and presentations. These were identified as platforms that promoted TK creation especially during the socialisation process as stipulated in the Wenger (1998)'s CoP model.

\section{Knowledge storage and retrieval}

This study sought to establish how the universities stored and retrieved TK and some of the responses from the interviews are as follows: 
1. "People are key tacit knowledge databases, but in most cases, we take care of the ICT facilities as storage and retrieval tools. People are not considered.

2. "Since this knowledge is too personal, it can only be stored and retrieved by the individual"

3. "Recording is done, slides which are shared via the corporate email and databases for access "

4. "Knowledge that exist in form of lecture notes and other materials are stored in electronic devices"

5. "Electronic devices, like the computer"

6. "Electronic databases"

7. "Files (largely explicit)"

8. "Virtual library"

9. "Institutional repository, in Kenya, UoN has the richest institutional repository"

Universities store knowledge in different ways and platforms. From the responses from the interviews above, it is clear that people were identified as important TK storage elements. Files and electronic databases were also mentioned as storage tools. It was also indicated by the respondents, that it was not easy to store TK through ICT since the knowledge is highly personalised. People are TK reservoirs. In universities, we have individuals who direct others, through mentorship and other ways like coaching and teaching. The "uncodified, is knowledge that cannot be easily prepared for transmission purposes such as, experiences" (Boisot, 1998, p. 59). Different employees have got different experiences depending with the working environment - context. "Uncodified and undiffused knowledge is referred to as individual knowledge such as, experiences, views, perceptions, and ideas. Besides people, tacit knowledge can also be documented and stored. Public knowledge is codified and diffused. This can be found in the library, books, journals, and newspapers" (Boisot, 1998, p. 59). Universities under study had repositories where TK was captured and stored. The ability to convert tacit into explicit knowledge makes it possible for encoding knowledge through physical memories, such as databases

\section{Knowledge sharing and transfer}

This research aimed at establishing how TK is shared and transferred. Several questions were posed to the interviewees who responded as follows:

1. "Skills transfer from senior researchers to junior researchers in laboratory/fieldwork"

2. "Knowledge transfer among staff in collaborative / interdisciplinary research"

3. "There are collaborative teams especially for writing research papers... "the tool used by the CUE to allocate publication points is discouraging. This is because the second and the third authors get minimal points yet the work is done by all of them, each team members' efforts matters a lot. I think that is why most researchers are not publishing"

4. "This is the key business of the division, this service was initially under the academic division, but after recognising its value it was split so as to give it the attention it deserves because the academic division is also too big. The division engages in capacity building and pushing the research agenda in the university. It supports disciplinary and multidisciplinary teams. The division has a large grants portfolio, and we are very proud of this. We mobilise staff and students and do a lot of capacity building. We also get the 
parties interested on board, we make agreements in terms of the expectations, time frame among others."

5. "Exchange of information, technology and skills through collaborative research and innovations"

6. "A lot of Information is passed through storytelling, "...it is the best since a lot is shared"

7. "The university has Sabbath classes where people share experiences also"

8. "Structures are flexible and supportive, make people feel free to interact"

9. "Rigid and complicated, appointments are booked"

10. "Official language of communication mainly is English"

11. "Informal meetings during tea breaks and lunch time enables some of us to brain storm"

12. "We have school board meetings every semester"

13. "Team building and exchange of ideas"

14. "In social forums, where people meet to discuss, can be in meetings, in class, team discussions, workshops, conferences, among others"

15. "There are a lot of mentorship activities in the universities, unfortunately we have no policy"

16. "Information sharing on social media"

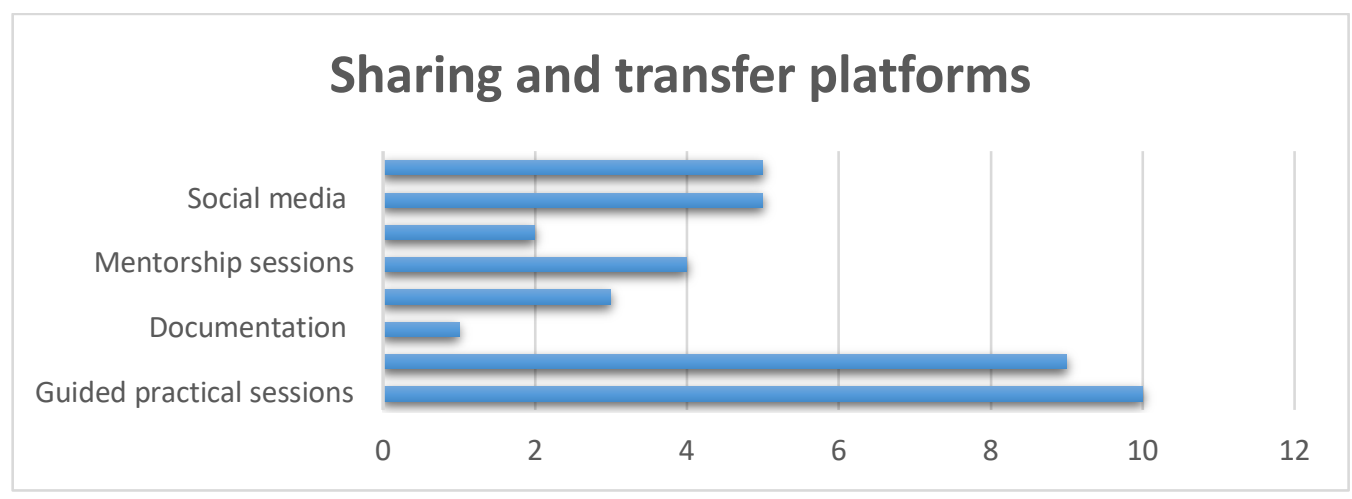

Figure 1. Sharing and Transfer Platforms

From above responses, it is identified: guided practical sessions, social interactions, documentation, teamwork/teams, mentorship sessions, social media and workshops, as well as conferences as platforms for TK transfer in universities. Practical sessions guided by lecturers in universities was also a form of TK transfer. Lecturers provide expert knowledge through practical lessons, where students are able to listen, observe and work out under supervision and later on, they can handle the practical alone without supervision. This process leads to trial and error sessions until things work out, which is a learning process. Social interactions among employees was found to be an important element for TK sharing and transfer in universities. Social interactions are supported by power/organisational structures. Power structures in the universities were found to be either flexible or inflexible and supportive or unsupportive. Where there were flexible and supportive power structures, skills were transferred from senior to junior employees with ease. During the social interactions, meetings were also revealed to be among the methods used for TK transfer and sharing in the four universities. Organisations should not only set clear 
meeting objectives, but top management should also support meetings in order for them to be successful. Additionally, "Tacit knowledge is transferred through conversation, storytelling, discussions, analogies, and demonstrations" (Mohajan, 2016, p. 7). Story telling was found to be a method of TK transfer in the universities, though it was not known to the respondents as a key strategy. During informal social gatherings, meetings and classroom sessions stories are told. Organisational stories are considered an effective way to capture and transmit TK.

This study established that the official language of communication at the universities is English. A common language is a prerequisite to knowledge transfer (Lemos, 2010). Keglovits (2013) stated that knowledge sharing requires excellent communication skills which is an essential knowledge transfer tool. Weak communication skills might lead to misunderstandings, less conversation and contact between the members in the universities, which prohibits TK flow. It was revealed that universities are using social media as way of transferring and sharing TK. This include Facebook, WhatsApp and short text messaging. Institutional repositories were also identified as a major database for TK transfer and sharing through the university websites. This implies that, technological tools and applications are used by universities to support TK sharing activities. This is supported by Laudon and Laudon (2012) who observe that social networking tools can support TK transfer in out of organizations. Workshops and conferences were also identified as platforms that facilitate TK sharing and transfer. Most universities organise for workshops and conferences to provide a chance to scholars and researchers to have academic discourse. In the process TK is exchanged and the participant are able to learn from the process. Mentorship in the four universities was said to be informal which would be best when structured: "providing a more equitable dispersion of mentoring opportunities and allowing organisational guidance in the information exchange process. Formalised mentoring also facilitates cross-unit mentoring, thus augmenting worker skill sets. However, the prerequisite for all successful mentor programmes includes participation, rewards and support for the worker and mentor" (Banacu et al., 2013, p. 495). Teamwork was found to be among the important strategies for TK creation and capture. During the data collection process, the researcher identified, meeting rooms, open spaces, resting shades, cafeteria and offices that allowed lecturers, students and other administrative staff to hold meetings (formal and informal) and discussions at different levels. However, it was also noted that the current system by the CUE in Kenya, discourages teamwork. This is because the members noted that, the reward scheme was mean, as indicated by the following quote:

"the tool used by the CUE to allocate publication points is discouraging. This is because the second and the third authors get minimal points yet the work is done by all of them, each team members' efforts matters a lot. I think that is why most researchers are not publishing". This indicates demotivated researchers who lack morale because of the reward system.

Collaborations through teams, internally or externally formed are interactive and dynamic. Macpherson et al. (2004) as well as Eriksson (2013) pointed out that "firms use various knowledgeintegration strategies, many of which rely on organizational interaction and collaboration routines" (p. 6). Universities have various collaborations that enable research and innovations in the institutions of higher learning in the country. Further, Cohen and Levinthal (1990), while later agreed by Ericksson (2013), who noted that: 
in analytical terms it is connected to absorptive capacity in that organizations with such capacity are better able to make use of the knowledge at their disposal. The sharing of tacit knowledge, in particular, is essential in the interaction between individuals. (p. 6)

Team spirit promote collaborative projects which fosters creativity and innovation which leads to new product design and development in organizations (Blomqvist \& Levy, 2006). Wilden (2016) added that "dynamic capabilities are essentially a multilevel phenomenon spanning individuals, groups/teams, business units, organizations, and alliances, and that much of the definitional confusion arises from a failure to account for the interactions across levels and between contexts" (p. 1027). Collaborations, whether internal or external add value to universities in the process of knowledge sharing and transfer hence should be made practical and encouraged.

One of the major characteristics of TK is its inability to share because it is highly personal. "Stickiness of tacit knowledge acts as a barrier to knowledge transfer and it is influenced by social embeddedness, which is characterized by close ties, trust and culture" (Sikombe \& Phiri, 2019, p. 9). This was revealed by this study as well where out of eight platforms for TK transfer only one (2.6\%) believed that TK must be transformed to tangible form before it is shared (Chugh, 2017).

Wenger (1998)'s CoP and Boisot (1998)'s I-Space models heavily support TK sharing in universities. TK sharing platforms, such as meeting spaces and rooms, social media networks and mentorship programmes have been identified by the current study to support the TK transfer and sharing process. "Social interaction in forms of face-to-face communication, conversation, verbalization, discussing, and dialoguing has been determined as a main perquisite for tacit knowledge sharing" (Panahi et al., 2012, p. 651) of which the CoP is one such social interaction platform. Universities have schools, departments and sections whose structures promotes interactions. The university is a domain with academic, non-academic staff and students who form a community where both formal and informal (practice) knowledge activities take place, hence promotion of TKS. A CoP offers "a flexible and operational approach of managing the complexities of" TK through its main components - domain, community and practice (Wenger et al., 2002, p. 71). Boisot (1998)'s model on the other hand, supports TKS through the SLC, fourth phase - diffusion (p. 59). Given the necessary structures and platforms, TK can be highly shared in the universities. This study outlines, social platforms, workshops and conferences, meetings where there exists one to many and many to many kinds of relationships. The more sharing the more TK is transferred hence more resources developed which positively affects the performance in the universities.

\section{Tacit knowledge application and use}

TK is an important asset as acknowledged by the interviewees. If it is well tapped and preserved it can promote service delivery and efficiency. Some respondents indicated the following ways in which TK can be applied and used as shown in Table 4. 
Table 4. Tacit Knowledge Application and Use

\begin{tabular}{|c|c|c|}
\hline Theme & Response & Interpretation \\
\hline $\begin{array}{l}\text { Work } \\
\text { processes }\end{array}$ & $\begin{array}{l}\text { 1. "To work" } \\
\text { 2. "In the course of service delivery" } \\
\text { 3. "During our normal working" } \\
\text { 4. "In the course of work/duty" } \\
\text { 5. "In our everyday work on campus" } \\
\text { 6. "While doing your core duties" } \\
\text { 7. "To do my work" } \\
\text { 8. "For my daily routine activities" } \\
\text { 9. "To serve my customers" } \\
\text { 10. "To attend to my students" } \\
\text { 11. "I use tacit knowledge to demonstrate in class" } \\
\text { 12. "For problem solving" }\end{array}$ & $\begin{array}{l}\text { TK is used to perform } \\
\text { organisational activities } \\
\text { and work processes. }\end{array}$ \\
\hline $\begin{array}{l}\text { Research } \\
\text { and } \\
\text { innovations }\end{array}$ & $\begin{array}{l}\text { 1. "Used to develop new knowledge" } \\
\text { 2. "Consultancy services" } \\
\text { 3. "Proposal writing" } \\
\text { 4. "We used our skills and experiences to make decisions, } \\
\text { write papers, teach" } \\
\text { 5. "In developing more products and works of research" } \\
\text { 6. "For product development" } \\
\text { 7. "Helps in coming up with innovative ideas among staff } \\
\text { 8. "Promotes creative thinking" } \\
\text { 9. "Facilitates the ideation process" } \\
\text { 10. "Supports research activities" }\end{array}$ & $\begin{array}{l}\text { TK is used to develop new } \\
\text { products and services. }\end{array}$ \\
\hline $\begin{array}{l}\text { Decision } \\
\text { making }\end{array}$ & $\begin{array}{l}\text { 1. "Helps in the decision making process" } \\
\text { 2. "In taking a stand" } \\
\text { 3. Provides insights" } \\
\text { 4. "For directions" } \\
\text { 5. "Assists in making a stand" } \\
\text { 6. "Informs decisions" } \\
\text { 7. "Helps in making decisions" } \\
\text { 8. "Supports administrative decisions" } \\
\text { 9. "Helps in decision making" } \\
\text { 10. "Helps in giving directives" }\end{array}$ & $\begin{array}{l}\text { TK supports decision } \\
\text { making process in the } \\
\text { universities. }\end{array}$ \\
\hline Mentorship & $\begin{array}{l}\text { 1. "In teaching and during mentorship" } \\
\text { 2. "Used in mentorship programmes" } \\
\text { 3. "supports mentorship activities" } \\
\text { 4. "Key element in mentoring" } \\
\text { 5. "Used during mentorship and coaching inexperienced } \\
\text { 6. "Daff" } \\
\text { 7. "During teaching" }\end{array}$ & $\begin{array}{l}\text { TK can be used during } \\
\text { teaching and mentorship } \\
\text { processes. }\end{array}$ \\
\hline
\end{tabular}

Table 5 presents ways in which TK is applied and used at universities in Kenya. Respondents identified, work processes, decision making, research and innovation and mentorship as key in 
supporting TK application and use. TK promotes service delivery and efficiency. It is important for universities to use TK created because it helps in the creation of new knowledge through processes like; integration, combination, invention and innovation for improved decision making. Individuals use TK to make decisions. "Tacit knowledge is partly or fully subconscious, deeply rooted in action, procedures, routines, commitment, ideas, value and emotions of individuals or groups" (Mládková, 2012, p. 105).

Table 5. Tacit Knowledge Application and Use

\begin{tabular}{|l|c|c|}
\hline Application and use & Frequency & Percent (\%) \\
\hline Decision making & 10 & 25.6 \\
\hline Mentorship and coaching & 7 & 18.0 \\
\hline Research and innovations & 10 & 25.6 \\
\hline Work processes & 12 & 30.8 \\
\hline
\end{tabular}

\section{Conclusion}

Human capital was found to be a key asset in TKM. Universities whose attention is focused towards other resources other than human capital are on their way to fail, since the current knowledge society does not recognise such institutions as knowledge intensive. "Human capital is employee's experience and expertise that can increase organizations performance. More performance of employees means more efficiency of organization to increase efficiency of added value" (Rehman et al., 2011, p. 9). These are skills that are unique to each individual, and lack of it can results in stagnation in the growth of universities. Performance is the output of all work processes in an organisation. Management of TK in Kenya in universities was seen to be transformed through TK creation and capture, TK storage and retrieval, TK transfer and sharing; and TK application and use. TK creation was found to be the most difficult and "tricky." Kenyan universities have inadequate formal structures to facilitate TK creation/capture. The university community acquire knowledge through many methods and strategies such as; learning processes, ICT tools, mentorship, workshops and conferences and documentation. Critical to TK creation are research and innovation teams, mentorship, codification (documentation), and the use of academic libraries as knowledge creators.

Knowledge storage is an important activity because it provides an organisation with the basis on which decisions are made basing on the preserved and stored content. Human resources are powerful TK storage systems and universities must maintain them for continuity and growth. Universities store and retrieve knowledge in different ways and platforms. Universities are using emails and electronic files to store and share the TK to be retrieved later. Institutional repositories were found to be the main storage facility. ICT is a support tool in the TK storage process. TK is highly personalised hence extracting from staff becomes a challenge that requires extraordinary efforts. Depending with the nature (public/private) and year of establishment, organizational goals and cultures (Vries et al., 2019), universities are at different stages, use different ways and strategies to share TK. This include; guided practical sessions, social interactions facilitated by (power/organisational structure, meetings, common language, \& informal discussions), social media, conferences and workshops, mentorship, teams, and documentation. Tacit knowledge was 
utilized and used in the universities in the following ways: mentorship and coaching, undertaking daily duties and activities at the workplace/work processes; decision making; and for developing new research and innovations. Universities use knowledge created to make improved decision making. Being, practical in nature, TK can facilitate handling of tasks in the institutions. Individuals are able to perform their duties by putting this kind of knowledge into use. Universities are cautioned to select the best employees, with the right skills and the human resource departments need to deploy the same in the rightful sections. This is because wrong skills are unproductive and will negatively impact performance. Staff should be deployed to the right department. This study revealed skills mismatch in some universities under study. TK in the universities has encouraged an environment for research. TK stimulates thinking, hence creativity and innovation whose output is product development. TK is a crucial input to innovation. Like any other study, limitations were not an exemption. This study was qualitative in nature where deans, directors of research and innovation, ICT and heads of planning division as well as head librarians in only four universities were purposively sampled hence, the cannot generalize the findings, therefore the researchers make a recommendation for further studies to be done in a broader scope and context to curb this limitation.

\section{Recommendations}

This paper makes the following recommendations based on the findings;

i) Since human capital is very crucial in the management of TK and further contributes to organizational performance, there is need for universities to manage human capital in a more organized manner. Employees who are equipped with knowledge can guide an organization to achieve its goals. Lack of TK results in stagnation in the growth of an organization. TK is considered the most important asset in universities in Kenya. This is backed up by Stifter (2013) who asserted that, in the current digital economy, the only factor that provides longterm competitive advantage is the knowledge of employees (TK). For this to be feasible, HLIs have to establish a TKM office or department which will take full responsibility of human capital/talent management. Once the human capital if catered for well, the rest of the TK assets will almost automatically fall in place. But if the institution focuses away from the human capital, even if other assets are put in place, the impact of TK on organizational performance may not be of significance. It is imperative for universities to invest in the human capital for TK to have the desirable impact on organizational performance.

ii) Universities in Kenya should put structures, mechanisms and policies that address human capital have been put in place. This will give them a chance to establish the knowledge needs of the organisations as well as available TK resources (what, who, where, \& how knowledge flow). The importance of a knowledge management policy for the public sector was indicated by a study conducted by the Institute for Applied Economic Research (IPEA) which states that: "the isolated initiatives; the dispersed efforts, often at the same ministry; the inexistence of communication and information sharing, both internally and between organisations, about KM practices; and the unfamiliarity with the subject among members of high administration, middle management and government employees in general, reveal that dissemination of knowledge in direct administration will only take place if a KM policy is implemented" (Fresneda \& Gonçalves, 2008, p. 12) 
Dewe and Wright (2007) indicated that "for ensuring a successful introduction of knowledge based initiatives in an organization, a knowledge based policy or strategy should be formulated" (p. 8). Policies are created to guide decision making in institutions. Wamundila (2009) supported the current study with his research findings on developing guidelines in establishing a KM policy at the University of Zambia. A TKM policy will help universities to develop their knowledge map which will be a starting point to TKM. Such a policy may be crucial to the contribution of TKM and organisational performance. The policy is important for picking up lessons, planning and implementing the best possible strategies for TK on organisational performance. Therefore, the paper strongly recommends a well-defined TKM policy to make this process a reality.

iii) Further to human capital improvement, is the establishment of formal mentorship programmes to facilitate TK transfer and sharing. This is can be made possible through establishment of mentorship directorates/departments to support the implementation process. Such programmes will build a base for human capital and a good knowledge base, that will augur well with enhanced structural resources. "However, the prerequisite for all successful mentorship programmes includes participation, rewards and support for the worker and mentor" (Banacu, 2013, p. 495), which is not the case in the universities studied.

iv) Universities should create an organisation culture that supports knowledge sharing, through fostering open and independent decision making, which is part of mentorship and role modelling. Banacu et al. (2013) supported by noting that it is important to, build "a knowledge sharing culture between all employees (e.g. setting up a structure of internal knowledge transfer amongst the employees). Employees must be given the time, space and opportunity to transfer and therefore share tacit knowledge which is transmitted verbally" (p. 498).

v) Additionally, universities should adopt a flexible organisational structure that promotes topbottom and bottom-up type of interactions. This encourages freedom of opinion and problem solving thus promotes trust which enhances social interaction which provides a TK creation, sharing and transfer context or environment. Mládková (2012) noted that "our society is historically hierarchical and managers of our organizations may have problems accepting that an important asset is hidden in the heads of their subordinates and they cannot control it directly" (p. 113).

vi) Universities should provide a research and innovations environment to encourage creativity. Innovation hubs, science parks and incubation centres should be established in universities. This will lead to production of products and services, like demand driven curricula, advanced systems, and patented innovations. Universities should establish internal and external collaborations for the purposes of research, interdisciplinary or multidisciplinary. This could be local, regional or international. This can be achieved when universities establish strategic partnerships with suppliers and the industry in order to build up their knowledge base and cut down on service costs.

vii) Universities need to design and establish knowledge management departments. This was conspicuously missing in the four universities studied. KM departments shall support the entire TKM lifecycle from creation to use. 


\section{References}

Alwis, R. G., Hartmann, E., \& Gemünden, H. G. (2004). The role of tacit knowledge in innovation management. Proceedings of the 20th Annual IMP Conference, Copenhagen, 1-23. https://www.impgroup.org/uploads/papers/4585.pdf

Awad, E. M., \& Ghaziri, H. (2007). Knowledge management. (e-book). Pearson Education. https://trove.nla.gov.au/work/16685926

Banacu, S. C., Busu, C., \& Nedelcu, A. C. (2013). Tacit knowledge management - strategic role in disclosing the intellectual capital. Proceedings of the 7th international management conference, 491-500. http://conference.management.ase.ro/archives/2013/pdf/57.pdf

Best J. W., \& Kahn J. V. (2006). Research in education (10th ed.). Pearson Education.

Bhardwaj, M., \& Monin, J. (2006). Tacit to explicit: An interplay shaping organization knowledge. Journal of Knowledge Management, 10(3), 72-85. https://doi/10.1108/13673271211218915/

Blomqvist, K., \& Levy, J. (2006). Collaboration capability-a focal concept in knowledge creation and collaborative innovation in networks. International Journal of Management Concept, 2(1), 31-48. https://doi.org/10.1504/IJMCP.2006.009645

Boisot, M. H. (1998). Knowledge assets: Securing competitive advantage in the information economy. Oxford University Press. https://doi.org/10.1093/acprof:oso/9780198296072 .001 .0001

Bonner, D. (2000a). Knowledge: From theory to practice to golden opportunity. American Society for Training \& Development, 6, 12-13. https://mpra.ub.uni-muenchen.de/83038/

Bonner, D. (2000b). The knowledge management challenge: New roles and responsibilities forchief knowledge officers and chief learning officers. In J. J. Phillips \& D. Bonner (Eds.), Leading knowledge management and learning, American society for training \& development, (pp. 3-19). American Society for Training and Development.

Canals, A., \& Boisot, M. (2004). Evolution of knowledge management strategies in organizational populations: A simulation model. https://www.researchgate.net/publication/240632484

Cheng, M. Y., Ho, J. S., \& Lau, P. M. (n.d). Knowledge sharing in academic institutions: A Study of Multimedia University Malaysia. Electronic Journal of Knowledge Management, 7(3), 313-324.

Chugh, R. (2017). Barriers and enablers of tacit knowledge transfer in Australian higher education Institutions. International Journal of Education and Learning Systems, 2, $277-$ 281.

Chugh, R. (2019). Tacit knowledge transfer: Information technology usage in Universities. Proceedings of the 11th International Joint Conference on Knowledge Discovery, Knowledge Engineering and Knowledge Management, 3, 349-355. https://doi.org/10.5220/0008355603490355 
Commission for University Education. (2017). List of universities accredited to operate in Kenya as at 2017: Public and private. CUE. http://www.cue.or.ke/index.php/downloads

Corbin, J., \& Strauss, A. (2008). Basics of qualitative research: Techniques and procedures for developing grounded theory ( $3 \mathrm{r}$ ed.). Sage Publications.

Davenport, T. H., \& Pursak, L. (1998). Working knowledge: How organisations manage what they know. Harvard Business School Press. https://doi.org/10.1145/348772.348775

Dewe, J. A., \& Wright, E. (2007). Connecting knowledge: Knowledge leadership framework for AUT University. http://www.caudit.edu.au/educauseaustralasia07/ authors papers/Dewe138.pdf

Dhamdhere, S. (2015). Importance of knowledge management in higher education institutes. Turkish Online Journal of Distance Education, 16(1), 162-183. https://doi.org/10.17718/tojde.34392

Eriksson, T. (2013). Processes, antecedents, and outcomes of dynamic capabilities. Scandinavian Journal of Management, 838, 1-18. http://www.hadjarian.com/reghabati/1-s2.0-S

Estrada, S. (2017). Qualitative analysis using R: A free analytic tool. The Qualitative Report, 22(4), 956-968. https://nsuworks.nova.edu/tqr/vol22/iss4/2

Fresneda, P. S. V., \& Gonçalves, S. M. G. (2008). Formulating a knowledge management policy of Federal public administration, the Brazilian experience. Chamber of Deputies, Publishing Coordination. http://www.rcc.gov.pt/SiteCollectionDocuments/KM Brazil$\underline{08 . p d f}$

Gallo, C. (2010). The innovation secrets of Steve Jobs. Insanely different. Principles for breakthrough success. McGraw Hill.

Gill, A. (2009). Knowledge management initiatives at a small university. International Journal of Educational Management, 23(7), 604-616. https://www.learntechlib.org/p/105194/

Haldin-Herrgard, T. (2000). Difficulties in diffusion of tacit knowledge in organizations. Journal of Intellectual Capital, 1(4), 357-365. https://www.emerald.com/insight/content/doi/10. 1108/14691930010359252/full/html

Haslinda, A., \& Sarinah, A, A. (2009). Review of knowledge management models. The Journal of International Social Research, 2(9), 187-198. http://www.sosyalarastirmalar.com/ cilt2/sayi9pdf/haslinda_sarinah.pdf

Hau, Y. S., Kim, B., Lee, H., Kim, Y. G. (2013). The effects of individual motivations and social capital on employees' tacit and explicit knowledge sharing intentions. International Journal of Information Management, 33(2), 356-366. https://isiarticles.com/bundles/ Article/pre/pdf/4390.pdf

Housel, T., \& Bell, A.A. (2001). Measuring and managing knowledge. McGraw-Hill.

Hoey, E. M. \& Kendrick, K. H. (2017). Conversation analysis. In A. M. B. de Groot \& P. Hagoort (Eds.), Research methods in psycholinguistics: A practical guide. Wiley Blackwell. 
Jakovljevic, M. (2012). A model of creativity, innovation and invention (MCII) from knowledge management perspective for interdisciplinary education. In S. Buckley, and $M$. Jakovljevic (Eds.), Knowledge management innovations for interdisciplinary education: Organizational applications. IGI Global.

Jakovljevic, M., Buckley, S., \& Bushney, M. (2013). Forming communities of practice in higher education: a theoretical perspective. Management, Knowledge and Learning International Conference, 1107-1119. https://www.researchgate.net/publication/ $\underline{263891940}$

Kabir, N. (2013). Tacit knowledge, its codification and technological advancement. Electronic Journal of Knowledge Management, 11(3), 235-243.

Keglovits, B. T. (2013). Sharing tacit knowledge in an organisation (Doctoral thesis). https://www.theseus.fi/bitstream/handle/10024/59991/

Keramati, A., \& Azadeh, M. A. (2007). Exploring the effects of top management's commitment on knowledge management success in academics: A case study. International Journal of Industrial and Manufacturing Engineering, 1(3), 59-64. https://waset.org/publications/ $\underline{10762 /}$

Khamali, R., Thairu, K., \& Rhoda, W. (2018). Influence of social media on knowledge sharing practices in Kenyan universities: A case of Strathmore University. The Strategic Journal of Business and Change Management, 5(4), 1816-1836.

Kidwell, J. J., Vander Linde, K. M., \& Johnson, S.L. (2000). Applying corporate knowledge management practices in higher education. Educause quarterly, 4, 28-33. https://er.educause.edu/ /media/files/articles/2000/12/eqm0044.pdf?la=en

Kipkebut, D. J. (2010). Organizational commitment and job satisfaction in higher educationalinstitutions: The Kenyan case. (Ph.D. Thesis). Middlesex University. London. http://eprints.mdx.ac.uk/6509/

Lahaie, D. (2005). The impact of corporate memory loss: What happens when a senior executive leaves? Leadership in Health Services, 18(3), 35-48. https://doi.org/10.1108/13660750

Laudon, K. C., \& Laudon, J. P. (2012). Management information systems: Managing the digital firm. Pearson Education.

Lee, J. (2000). Knowledge management: The intellectual revolution. IIE Solutions, 34-37. https://www.researchgate.net/publication/292446031

Lee, G. C., \& Nissen, M. E. (2010). Accelerating acculturation through tacit knowledge flows: Refining a grounded theory model. VINE, 40(3/4), 312-325. https://doi.org/10.1108/03055721011071430

Mahroeian, H., \& Ferozia, A. (2012). Challenges in managing tacit knowledge: A study on difficulties in diffusion of tacit knowledge in organizations. International Journal of Business and Social Science, 3(19), 303-308. http://ijbssnet.com/journals/Vol_3_No_19_October_2012/34.pdf 
Martin, J. S., \& Marion, R. (2005). Higher education leadership roles in knowledge processing. The Learning Organization, 12(2), 140-151. https://doi.org/10.1108/09696470510583520

Mayfield, M. (2010). Tacit knowledge sharing: Techniques for putting a powerful tool in practice. Development and Learning in Organization, 24(1), 24-26. https://doi.org/10.1108/14777281011010497

Mládková, L. (2012). Sharing tacit knowledge within organizations: Evidence from Czech Republic. Global Journal of Business Research, 6(2), 105-115.

Ministry of State for Planning, National Development and Vision 2030. (2012). Sessional paper No. 10 of 2012 On Kenya Vision 2030. Office of the Prime Minister Ministry of State for Planning, National Development and Vision 2030. http:/vision2030.go.ke/inc/uploads/ 2018/05/Sessional-paper-No.-10-of-2012-On-Kenya-Vision-2030.pdf

Mohajan, H., K. (2016). Sharing of tacit knowledge in organizations: A review. American Journal of Computer Science and Engineering, 3(2), 16-19. https://mpra.ub.unimuenchen.de/82958/

Mohajan, H. R. (2017). The roles of knowledge management for the development of organizations. https://www.researchgate.net/publication/314063315

Mongkolajala, H., Panichpathom, S., \& Ngarmyarn, A. (2012). The development of tacit knowledge sharing behavior among employees in organizations. International Journal of Business and Social Research, 2(5), 158-163. https://thejournalofbusiness.org/index.php/ site/article/view/106

Mungai, G. C. N. (2014). Tacit knowledge management in public institutions in Kenya: A case of the Kenya institute for public policy research and analysis (KIPPRA). (Master's Thesis). University of South Africa, South Africa. https://www.researchgate.net/publication/ $\underline{314062981}$

Ng'ethe, J. M., Iravo, M. E., \& Namusonge, G. S. (2012). Determinants of academic staff retention in public universities in Kenya: Empirical review. International Journal of Humanities and Social Science, 2(13), 205-212. http://www.ijhssnet.com/journals/Vol_2 No_13_July_2012/22.pdf

Nonaka, I. (1994). A Dynamic theory of organizational knowledge creation. Organization Science, 5(1), 14-37. http://www.jstor.org/stable/2635068

Nonaka, J., \& Takeuchi, H. (1995). The knowledge-creating company. Oxford University Press. https://global.oup.com/academic/product/

Nonaka, I., Toyama, R., \& Konno, N. (2000). SECI, Ba, and leadership: A unified model of dynamic knowledge creation. Long Range Planning,33, 5-34. https://doi.org/10.1016/ S0024-6301(99)00115-6

Omotayo, F. O. (2015). Knowledge management as an important tool in organizational management: A review of literature. Library Philosophy and Practice, (1238), 1-23. http://digitalcommons.unl.edu/libphilprac/1238 
Onchiri, S. (2013). Conceptual model on application of chi-square test in education and social sciences. Educational Research and Reviews, 8(15), 1231-1241. https://doi.org/10.5897/ ERR11.305

Ondari, O., \& Minishi, M. (2007). Enhancing governance, performance effectiveness and capacity to deliver basic government services in Sub-Sahara Africa through knowledge management. Proceedings the Knowledge Management Africa (KMA) Second Biennial Conference, Nairobi.

Palmer, P.J., Zajonc A., \& Scribner M., (2010). The heart of higher education, a call to renewal: Transforming the academy through collegial conversations. Jossey-Bass.

Panahi, S., Watson, J., \& Partridge, H. (2012). Social media and tacit knowledge sharing: Developing a conceptual model. World Academy of Science, Engineering and Technology, 64, 1096-1102. https://eprints.qut.edu.au/50068/

Patton, M. Q. (2002). Qualitative research and evaluation methods (3rd ed.). Sage Publication.

Patil, D. M. (2018). Application of chi-square test in social science research. International Journal of Advance Research in Computer Science and Management Studies, 6(8), 1-7.

Polanyi, M. (1966). The tacit dimension (1st ed.). Doubleday. https://books.google.co.ke/books

Rowley, J. (2000). Is higher education ready for knowledge management? The International Journal of Education Management, 14(7), 325-333. https://doi.org/10.1108/09513540 010378978

Ryan, S., \& Lero, R.V. O. (2012). Social interaction, team tacit knowledge and transactive memory: Empirical support for the Agile approach. https://ulir.ul.ie/bitstream/handle/10344/2698/Ryan_2012_social.pdf?sequence=2

Sacks, H. (1992). Lectures on conversation (Vols. 1 \& 2). Blackwell.

Sharkie, R. (2005). Precariousness under the new psychological contract: The effect on trust and the willingness to converse and share knowledge. Knowledge Management Research \& Practice, 3(1), 37-44.

Schegloff, E. A. (1995). Discourse as an interactional achievement III: The omnirelevance of action. Research on Language and Social Interaction, 28, 185-211.

Serban, A. M., \& Luan, J. (Eds.) (2002). Knowledge management: Building a competitive advantage in higher education. New Directions for Institutional Research,113. https://www.researchgate.net/publication/272295725

Sikombe, S., \& Phiri, M. A. (2019). Exploring tacit knowledge transfer and innovation capabilities within the buyer-supplier collaboration: A literature review. Cogent Business \& Management, 6, 16-31. https://doi.org/10.1080/23311975.2019.1683130

Smith, E. A. (2001). The role of tacit and explicit knowledge in the workplace. Journal of Knowledge Management, 5(4), 311-321. http://www.emerald-library.com/ft

Stifter, V. (2013). The role of emotional intelligence in knowledge sharing. RELIK, 24, 9-10. https://relik.vse.cz/static/2013/sbornik/download/pdf/93-Stifter-Viktoria-paper.pdf 
United Nations Development Programme, UNDP. (2015). Sustainable development goals. https://www.undp.org/content/undp/en/home/librarypage/corporate/sustainabledevelopment-goals-booklet.html

Vahedi, M., \& Irani, F. N. H. A. (2010). Information technology (IT) for knowledge management. Procedia Computer Science, 3(2011), 444-448. https://www.sciencedirect.com/science/article/pii/S1877050910004497

Vries, E. W., Dolfsma, E., Windt, H. J., \& Gerkema, M. P. (2019). Knowledge transfer in university-industry research partnerships: a review. Journal of Technology Transfer 44, 1236-1255. https://doi.org/10.1007/s10961-018-9660-X

Wah, L. (1999a, April). Behind the buzz. Management Review, 17-26.

Wah, L. (1999b, May). Making knowledge stick. Management Review, 24-29.

Wamundila, S. (2009). Developing guidelines for a knowledge management policy to enhance knowledge retention at the University of Zambia. UNISA, South Africa. uir.unisa.ac.za

Wenger, E. (1998). Communities of practice: Learning, meaning, and identity. Cambridge University Press. http://dx.doi.org/10.1017/CBO9780511803932

Wenger, E. (2010). Communities of practice and social learning systems: The career of a concept. In C. Blackmore (Ed.), Social learning systems and communities of practice (pp. 179-180). The Open University/Springer-Verlag. https://doi.org/10.1007/978-1-84996$133-211$

Wenger, E., McDermott, R., \& Snyder, W.M. (2002). Cultivating communities of practice: A guide to managing knowledge. Harvard Business School Press. http://cpcoaching.it/wpcontent/uploads/2012/05/WengerCPC.pdf

Whyte, G., \& Classen, S. (2012). Using storytelling to elicit tacit knowledge from SMEs. Journal of Knowledge Management, 16(6), 950-962. https://doi.org/10.1108/13673271211276218

Wilden, D., \& Dowling (2016). The architecture of dynamic capability research identifying the building blocks of a configurational approach. Academy of Management Annals, 10(1), 997-1076. https://www.researchgate.net/publication/325003653

World Bank. (2012). Knowledge for development programme (K4D). http://go.worldbank.org/ 8DG6O1F0I0

Zhao, Y. (2013). Tacit knowledge transfer from manufacturing firms to suppliers in new product development: A study of suppliers. International Journal of Information and Education Technology, 3(5), 571-574. http://www.ijiet.org/papers/337-k1006.pdf 


\section{Authors Biographies}

Joan Wakasa Murumba, MSc. is an assistant lecturer of Information Science and also the Head of Department of Computer Science and Informatics at Karatina University, Kenya. Formerly she worked as a Librarian at Kenya Methodist University and also as an editorial consultant with various academic publishing firms in Kenya. Currently, she is undertaking her PhD studies at Kisii University and her research area is tacit knowledge management. Her life glows

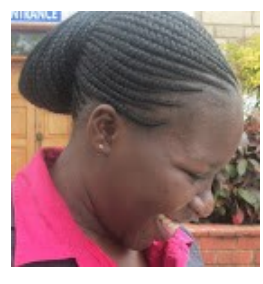
with thrilling and relentless passion for academic, scholarly research and inspirational books with a bias in information and knowledge management. She has authored several referred journal articles in knowledge management, eLearning and librarianship in addition to paper presentations in conferences both local and international. Her passion for human welfare has seen her participate in a number of community outreach projects that touches on environmental, health and entrepreneurial matters. The wheel for information dissemination is rolling and through Gods' grace, she believes that more work shall be made available to the public especially in academia.

Tom Kwanya, Ph.D. is an associate professor in the Department of Information and Knowledge Management at the Technical University of Kenya. He is currently also serving as the Director of the School of Information and Communication Studies. Prior to joining academics fulltime in 2013, he worked as a consultant on public information and knowledge management. He has authored several refereed journal articles, book chapters and conference papers.

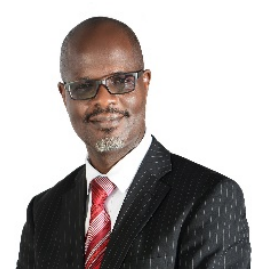
He has also edited two books and authored two monographs. His current research interests include organisational knowledge management, indigenous knowledge management, technology in information and knowledge centres, big data, infodemiology, and Internet of Things. Prof Tom Kwanya is also a research fellow in the Department of Information Science, University of South Africa.

Jane Cherono Maina, Ph.D. is a senior lecturer of Library and Information Science and the current chair of department of Library and Information Science under the faculty of Information Science and Technology at Kisii University. She has authored several refereed journal articles as well as presented papers in conferences both local and international with a bias in information ethics, information seeking behaviour and blended librarianship. Dr. Maina holds a BSc. Information Sciences, MSc. Library and Information Science and PhD

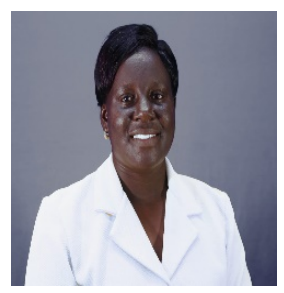
Library and Information Science all from Moi University, Kenya. Prior to joining the faculty, Dr. Maina was a librarian in the same University. 